Portland State University

PDXScholar

1975

\title{
The Use and Evaluation of Gestalt Techniques in a Program for the Parents of Handicapped Children
}

\author{
Richard Roy Hammond \\ Portland State University \\ Robert E. Phillips \\ Portland State University
}

Follow this and additional works at: https://pdxscholar.library.pdx.edu/open_access_etds

Part of the Social Work Commons

Let us know how access to this document benefits you.

\section{Recommended Citation}

Hammond, Richard Roy and Phillips, Robert E., "The Use and Evaluation of Gestalt Techniques in a Program for the Parents of Handicapped Children" (1975). Dissertations and Theses. Paper 1817. https://doi.org/10.15760/etd.1817

This Thesis is brought to you for free and open access. It has been accepted for inclusion in Dissertations and Theses by an authorized administrator of PDXScholar. Please contact us if we can make this document more accessible: pdxscholar@pdx.edu. 
THE USE AND EVALUATION OF GESTALT TECHNIQUES IN A PROGRAM EOR TILE PARENTS OF HANDICAPPED CHILDREN

\author{
by \\ RICHARD ROY HAMMOND \\ and \\ ROBERT E. PHILLIPS
}

\begin{abstract}
A practicum submitted in partial fulfillment
for the degree of
\end{abstract}

MASTER OF SOCIAL WORK

Portland State University

1975 
Approved:

B. Jom Hale, M.S.W., M.P.H.

Practicum Advisor 
ACKNOWLEDGEMENT

We wish to express our deepest appreciation to Mr. B. John Hale, M.S.W., M.P.H. for his inspiration and guidance. His skill in the use of Gestalt techniques is the foundation upon which this paper is based. 
LIST OF FIGURES

FIGURE

PAGE

1 Paradigm: Effect of Balancing Factors in a Stressful Event . . . . . . . . . . 
TABLE OF CONIENTS

PAGE

ACKNOWLEDGEMENT . . . . . . . . . . . . . . . LIST OF FIGURES . . . . . . . . . . . . . . . . . iv CHAPTER

I INTRODUCTION ................ 1

II PARENT EDUCATION IN THE "TOTS" PROGRAM . . . . . 3

III PARENTS OF HANDICAPPED CHILDREN . . . . . . 14 Crises................. 23

IV FUNDAMENTALS OF GESTALT IN PARENT EDUCATION $\cdots \quad . \quad 30$

$\checkmark$ THE USE OF THE PERSONAL ORIENTATION INVENTORY

AS AN EVALUATION TOOL ............. 46

Administration and Scoring ...... 48

Conclusion . . . . . . . . . 54

BIBLIOGRAPHY . . . . . . . . . . . . . 56 
CHAPTER I

INTRODUCTION

This practicum has grown out of the authors' involvement in the parent education aspect of the "Tots" Prograrn which was held at the Child Development and Rehabilitation Center of the University of Oregon Health Sciences during the summer of 1974. At that time, it became apparent to us not only that parents of handicapped children face a multitude of problems in dealing with the daily management and care of their children, but also that having a handicapped child had a tremendous emotional impact and often affected how the parents felt about themselves. In order to examine and explore these underlying parental feelings, Gestalt group therapy was incorporated into the Parent-Education Program. The purpose of using Gestalt therapy was to help these parents get in touch with their feelings about having a handicapped child and to explore the ways in which these feelings may have been blocking their adjustment to the situation in which they found themselves.

Our underlying assumption is that the parents' emotional reaction will have an effect on their ability to deal with the special problems which their child presents.

The goal of this paper will be to further explore the use of Gestalt therapy in the Parent-Education Program and to find a way in which its effectiveness in freeing parents of emotional barriers to 
growth can be evaluated. Our speeific objectives will, therefore, be to; (1) review the literature and present our own assumptions on parental responses to having a handicapped child, (2) explore the basis of Gestalt therapy and relate it to the needs of parents who have handicapped children, (3) describe the setting in which the Parent-Education Program and its Gestalt component takes place, and (4) suggest the use of the Personal 0rientation Inventory (POI) as an appropriate tool for future use in evaluating the effectiveness of the Gestalt component of this program. 
CHAPTER II

PARENT EDUCATION IN THE "TOTS" PROGRAM.

The history of crippled children's services in oregon began in 1914 when members of the Federated Women's Club in Eugene made arrangements with an orthopedist to examine and treat a number of children who were in need of medical attention. This progran, along with the realization of the importance of healthy children to the state, led the Oregon Legislature in 1917 to enact a law relating to the care of handicapped children. The law placed the responsibility for such care with the University of Oregon Medical School. In a pamphlet titled "Information for Physicians" it states that the legal base of the services are spelled out in an Oregon 1 aw relating to crippled children's services found under statutes $444.010-444 .-050$. These statutes enable the medical school to receive funds and administer a program to improve services in locating crippled children and providing medical and other services for them.

In 1964, the Crippled Children's Division (CCD) began a demonstration clinic on the hypothesis that children with mental retardation must be in as near a normal state of health as possible before they can learn their maximus potential.

At about this time, federal legislation established the universityaffiliated concept under Public Law $\$ 88-164$. The objective of this legislation was to develop the programs and the facilities to evaluate 
mentally retarded children and at the same tine to train medical, dental and allied health students and professionals to care for the retarded in order to alleviate the manpower shortage in this field.

The Child Development and Rehabilitation Center (CDIC), consisting of an east section and a north section totaling 230,500 gross square feet, was conpleted in October, 1970. The cost of the two structures was $\$ 3.7$ million, including all furnishings.

The major aim of $C C D$ is to find the children who need help and then guide their parents to the best source of help. This is done by offering all services and resources of the medical schools as well as those of the physicians of the state to children who are handicapped or crippled.

Prior to 1970 , a relatively small percentage of the patient population seen by the M. D. Clinic consisted of children under four years of age. From the children seen by the clinic prior to 1970 , it soon became apparent to the CDRC staff that short-term evaluations were not adequate for these children. The greatest need was for a combination of parent-evaluation and parent-education with a greater emphasis upon the parent-education aspect of the program. Parents of children with developmental delays, it was learned, needed a great deal of background in understanding the nature of their problem and how they can best cope with the child's deficit in order to assist him in developing the potential that he has to the fullest.

Thus, in late fall of 1970 the Nutrition Division formed a small committee to plan and organize a "Tots" Program to meet these unmet needs. The overall plan was to utilize the interdisciplinary approach 
to a complete medical-behavioral evaluation of the children, along with a fairly intensive parent-education program. It was believed at that time that many of the problems parents have with the handicapped child, if dealt with early enough, would not develop into sexious management or behavior problems which would be much more difficult to control or eliminate dater.

This Coordination Comittee for the "Tots" Program consisted of Dr. Elaine Lis, Nutritionist, Mrs. Lillian Cunningham, Nutritionist, Miss Ester Kelly, Nurse, Mrs. Doris Julians, Nurse, Miss Diane Foster, Child Development Specialist, and Mrs. Sue Wright, Occupational Therapist. The primary goals set up for the "Tots" Program were as follows :

1. To provide a setting for medical, behavioral and developmental observations and assessments of the children.

2. Utilize assessment of the child as basis for beginning approaches to (a) stimulation of language abilities, (b) stimulation of motor abilities, (c) promotion of self-help skills, and (d) promotion of socialization skills.

3. Assist parents through guided observation and planned demonstrations to (a) promote parental recognition of the child's developmental abilities, and (b) learn methods and techniques to encourage the child to advance in all developmental areas.

4. Provide formal (group) and informal (individual) opportunities for parents to share common concerns and receive information and counseling in the area of child development.

5. Provide anticipatory counseling for management needs and 
developmental changes.

6. Provide educational planning for each child.

The criteria set by the staff for the entry of a child into the "Tots" Program in general were:

1. The child should be able to benefit from a longer, more intensive period of observation and evaluation than available in short evaluation processes. Referrals from short evaluations are also appropriate.

2. The child's handicap would be of some learning value to the students training at CDRC.

The specific criteria for entry into the "Tots" Progran include such things as:

1. Age categories (age range should emphasize approxinate functioning level rather than chronological age) although too great a disparity in physical size is avoided. Age range for tots is one to four years and four to seven years.

2. Presence of a handicapping condition (mental, physical, emotional, or multiple handicaps) which results in delayed functioning.

3. Parental desire and need for education and/or counseling related to their child's handicap.

other variables important in selecting a group to participate in the "Tots" Progran ares

1. Geographic proximity or local housing.

2. Available transportation.

3. Commitment to the program on the part of parents or referring source. 
accident prevention, developmental landmarks, etc.

4. Dental health.

5. Toilet training.

6. Essentials of good nutrition and development of self-feeding skilis.

7. Communication development.

8. Play development, i.e., development of gross and fine motor skills.

9. Behavior management.

10. Educational planning.

11. Summary and identification of unnet needs.

The purpose of such a program is to sustain and strengthen individual parents who are trying to handle similar problems and, thus, to halt the unbearable feeling of being alone and isolated. The ain of the program is to:

1. Provide a forum for parental discussion of current child care concerns.

2. Promote parental recognition of the child's developmental abilities.

3. Provide anticipatory counseling for management needs and levelopmental changes.

4. Restore or refuse the efforts of the parent to deal with the problem(s) with which they find themselves.

Put another way:

Parent education in small groups is effective in, helping parents with the tasks of child rearing, in preventing social problems, in lessening certain sources of psychological pressure, 
and in modifying deficits in the parencs feeling of self-worth and identity. Group support increased perspective and realify orientation, improved understanding of child development and fawily interaction, broadened knowledge of alternace ways of dealing with family situations. Such groups can be planned to aim toward specific points of stress in families, such as physical or environmental handicaps or special critical times in the development process. To a degree, these groups free members to make greater use of their capacities for healthy parental functioning. (M.S. Grow, 1967, p. 162)

Over the course of time in our work, it became apparent that most children in the "Tots" Program could not derive maximum benefit from the center program without simultaneous help for parents to understand their own feelings and attitudes toward the child. We found like Auerbach

(1959, pp. 18-19) when parents entered the program they wanted

first of all, up to date and accurate scientific information in language they can understand, regarding (I) their children's illness, (2) the effect the disability may have on the usual chart of normal child deveiopment. (3) the emotional aspects of the illness, (4) and the way in which it may affect the children's personalities and behavior. They want to know, very practically, what they can do to help their children develop to their best capacity, and what they may expect this capacity to be. In other words, they want to know how to manage now and what they have to look forward to.

These are the questions they often bring first to professional people, with a very strong sense of urgency. It is only later that they reveal that they need to know more about themselves, about their own widely conflicting but normal feelings, and their own special level of tolerance of the demands that are put upon then.

We found that parents participating in the Parent-Education Program came with an accumulation of months, and frequently years, of pain, distress, helplessness and dispair. Many of the parents still did not or could not accept that sorething was urong or different about their child. Because of these underlying feelings about the child, we found it to be difficult to teach behavioral management skills to parents or 
to try to educate the parents on conditions they could not accept.

Movement in the parent education group appeared to bagin with a rather anecdotal discussion of daily problems and pressures, and then gradually moved into a phase which night be called "grief work" interrupted or repressed in the past. He discovered that what most of the parents needed was a very simple thing which was nothing more than a chance to talk, without explanation or apology, about their child. Because social work values emphasize the importance of the individual's self-fulfillment and growth, the social worker dealing with parents in a parent education group places great emphasis on the importance of parental understanding, obtaining parental participation, and helping parents to carry out a plan or deal with a problem in their own way. This emphasis stems from the social worker starting where the group is by trying to see through their eyes and endeavors in order to understand the meaning of the handicapped condition to the parent. In man's search for meaning, Viktor Frankl (1963) says that

the role of the therapist is like that of an eye specialist as opposed to that of a painter. Whereas, a painter tries to present a picture of the world as he sees it, an ophthalmologist tries to help his patient see the world as it really is for him. The therapist broadens his client's visual field and so helps him see a full spectrum of actions, feelings, meanings, and values.

Regardless of where the social worker finds the parent of the retarded or handicapped child, the emphasis should be focused on the release of existing tensions and the strengthening of the parent selfconfidence.

Louise Shoemaker (1963) feels that if we use a group for social work purposes, then we must take into account the role of feelings. 
Social group work like social casework, is based on the conviction of the wholeness of the person, on his essential participation in the creation of himself, and the primacy of the emotions in the life of the individual. It rests firmly in the belief that change in feelings in one area of the person's life-pattern affects the total person. It assercs that significant interaction can occur in a group, setting in motion the "taking in" and the change in the person. The group can provide the experience of the acceptability of the self to others and thus to oneself, thereby affirming strength and identity on which further moverient can be based. The importance of encouraging the parents to express their feelings can scarcely be overestimated for the success of the parent and child relationship and educational understanding of the child's handicap may depend upon it. However, to facilitate this process requires the use of therapeutic techniques designed for this purpose. Because as Harriet Rheingold (1945, p. 164) stated,

a parent does not parade these feelings; in fact, he struggles to repress them and hesitates to admit them, even to himself. But until he can obtain relief from guilt, inadequacy, or humiliation, he cannot view reality with sufficient objectivity to develop emotional acceptance of his child.

Recognizing this as a possible barrier to an effective education program for the parents of handicapped children, we introduced Gestalt therapy into the Parent-Education Program during the summer of 1974. Gestalt therapy was chosen as a therapeutic technique because of its holistic orientation, and because it allows the parents to go only as far into their feelings as they want to go. The primary aim of introducing Gestalt into the Parent-Education Program was to assist the parents in arriving at some resolution of the 
painfully conflicting feelings that may tormers them, and to resolve the distortions of reality that lead to irrational planning.

Some of the objectives we set when we incorporated Gestalt into the Parent-Education Program were:

1. To help the parent to gain an intellectual understanding of his crises.

2. To help the parents bring into the open their present feelings to which thay may not have access. The person may have (to hitiself) repressed unacceptable feelings. There also may be denial of grief, feelings of guilt, or incompletion of the mourning process.

3. To reduce tension by providing means for the individual to recognize these feelings and bring them into the open.

4. To explore the parents' coping (defense) mechanisms in order to assist the parents in examining alternative ways of coping and examining ways of better utilizing existing mechanisms.

5. To reopen the social world of the parent by exploring ways which they deal with the reaction of others to their child.

6. To assist the parent in making realistic plans for the future. When the above goals are achieved through the use of Gestalt therapy techniques, we would expect the parents to experience a state of selfactualization, self-satisfaction, and become more calm and selfconfident. This would aide them in becoming more skillful at helping their child develop to his/her maximum potential. Blanche wille (1961) states that parents who have achieved a more objective perspective in their experience with the retarded chlld can discipline with more comfort, confidence and success. Furthermore, a parent who feels more 
confident and emotionally comfortable will be able to concentrate on materials presented in the other aspects of the Parent-Education Program more positively.

In summary, the ultimate success of any program designed to help parents of handicapped children must depend in part on the parents' attitudes and thinking, which cannot be clear if based on conflicting judgments, doubts, and veiled statements.

The value of a Parent-Education Program as mentioned by A. B. Auerbach (1959) is that it has a value, not as a substitute, but in and of itself, contributing in a very positive sense to the parents' growth and increasing strength in a way that often camot be achieved in other ways. This comes about through the exchange of ideas and experiences among the parents which takes place within the protection of the group. Ihis of ten enables the members to bring out feelings they are more hesitant to reveal in a one-to-one relationship. Their reluctance to do so in their individual contacts with medical, nursing, and social work personnel may stem from their fear of jeopardizing services which they so desperately need. In these groups, the parents seem to gain courage from the other group members; the dam bursts and ideas and feelings pour forth. Once they are out, the parents seems better able to look at their situation more realistically. 


\section{CHAPTER III}

PARENTS OF HANDICAPPED CHILDREN

Parenthood is perhaps one of the most difficult tasks that an individual ever undertakes. A parent is not only responsible for meeting his child's physical needs of adequate amounts of sustenance and shelter but must also provide the nurturance and guidance necessary to channel and direct the child into becoming an integrated individual. Parents are responsible for providing the child with an environment. where he can successfully learn the basic social roles and values of his society, its language, and the accepted adoptive techniques for functioning within that society. Parenthood has been described as a "consuming role". (Perlman, 1963) and the truth of this description seems selfevident.

In our society, the tasks of parents have grown even more difficult because of the increasing isolation of the nuclear family which forces parents to assume additional roles that would in the past have been taken over by other relatives. Lidz (1968, p. 66) describes this situation:

Without the help of relatives, the wife must often be mother, housekeeper, laundress, cleaning woman, and cook; she is supposed to provide the major companionship for her husband and be a stimulating sex partner or consider herself a failure as a woman.... The husband, in turn, finds that in addition to earning a living he is required to be an auxilliary nursemaid, a general handyman, gardener, playmate for his children, and companion for his wife.

In light of the tremendous responsibilities of parenthood, it is 
not surprising that many parents approach this situation with a high degree of ambivalence (Gardner, 1959). Yet, children are highly valued in this society and there are few parents who would part with their children willingly.

While the tasks and problews faced by the parents of a normal child seem difficult, they begin to pale when compared to those fared by the parents of handicapped children. Economically, socially and emotionally these parents have a tougher row to hoe. What will be focused on here is the literature concerning the emotional impact that having a handicapped child has on a parent.

One of the problems that all parents face when they discover that their child has a physical or mental handicap is that they must revise their previous expectations for that child. This is often a difficult process because in our culture children are often viewed by their parents as ego-extensions capable of satisfying parent-centered needs. Roos (1963) points out that parents closely identify with their children "taking pride in his accomplishments and basking in his reflected glory" but goes on to say that any serious defect in the child is interpreted by the parent as his own defect. Cummings, Bayley and Rie (1966) further elaborate this point by inferring that variations in the child's abilities and characteristics directly influence the parents' perceptions of their own worth and further that it affects their evaluations of other persons and events as well.

Ryckman and Henderson (1965) have delineated six areas of meaning which they feel children have for their parents and have elaborated how in each of these areas the parents of handicapped children are 
frustrated. Sumnarized, these areas of neaning are:

1. Parents view their children as physical and psychological extensions of themselves. Cumaings and Stook (1962) and Solnit and Stark (1961) have also commented on this point stating, in essence, that what is good about the child is a reflection of the good in the paxents and what is wrong with the child is interpreted as a reflection of what is bad in the parents.

2. children are a means of vicarious satisfaction for their parents. This area of meaning strikes back to the age-old belief that the parents" progency will be able to accomplish what the parents never could. Rychman and Henderson (1963, p. 106) point out that "the parents of the retarded are denied these rewards."

3. The third area of meaning is that they enable the parent to "transcend" death. Parents of handicapped children, especially if they only have one child, often are greatly disappointed by the prospect of the end of the family name and traditions.

4. Parents use children as personalized love objects but because of the resentment and guilt which parents of handicapped children have, they are prevented from forming a wholehearted attachment.

5. Parental feelings of worth in meeting the dependency needs of the child. Since dependency needs of a handicap child are greater than for a normal child, parents usually gain some satisfaction in this area. 6. All parents have negative feelings about the limitations and demands of child rearing but in the case of children with handicaps, limitations and demands are increased while expectations must be decreased. 
French, Levbarg, and Michael-Smith (1953) have elaborated on the fact that while the parents of average children can use their own life as a model for guiding their children, parents of the handicapped are clenied this opportunity. Wuch of the common experimental ground between parent and child is lost resuiting in frustration and feelings of inadequacy. Wolfenberger (1967) and 0lshansky (1962) discuss the fact that although having a handicapped child deprives the parents of the sense of certainty that they would have had with a normal child, it replaces it with another kind of certainty which is one of long-term dependency needs and extended demands on the parents' time and energy. In a later article, 01shansky (1966, p. 120) expands on this topic stating that:

Being a parent of any child is an extrenely strenuous role to fulfill, since conflicts, heartbreaks, and frustrations are inevitable by-products. What often sustains parents of normal children is the knowledge that ultimately their childxen will grow up, become self-supporting, and leave home. For the parents of the mentally defective, continuing dependency is their lot.

While 0lshansky here is speaking only of parents of mentally defective children, it should be pointed out that the parents of physically and emotionally disabled children also face a longer period of time that their children are dependent on them than do the parents of average or normal children.

Solnit and Stark (1961) in comparing maternal reaction to a dead child and maternal reaction to the birth of a defective child noted several similarities. In both situations, they noted feelings of loss, intense longing for the desired child, resentment of the cruel blow which fate had struck, and guilt over the possible responsibility for the death or defect. They went on to note the main difference between 
the two groups of mothers was that the nother of the defective child was faced with having to meet the ever present needs for care and attention of her defective child at the same tine that she was mourning the loss of the desired normal child. Maudelbaun (1967) also observed that parents upon learning of their chlld's handicap entered a period of mourning and grief accompanied by emotional isolation and loneliness. He went on to describe these parents as "feeling like exiled aliens in a world that has turned suddenly and unexpectedly harsh and cruel" (p, 227). Roos (1963) too noted that parents manifested typical grief reactions when they learned that their child was retarded but he also pointed out that this reaction seemed most severe in highly intelligent parents who tended to equate being human with the possession of intelligence.

01shansky (1962) has proposed that most parents of handicapped children suffer from a pervasive psychological reaction which he identifies as chronic sorrow. He describes this reaction as a "non-neurotic response to a tragic fact" and goes on to state that it lasts as long as the child lives. He theorizes that professionals must, in light of this response, grant parents a long period of time in which to adjust their feelings and organize their resources so that they can meet their child's needs.

If the premise that many parents react to the knowledge of a handicap in their child by manifesting a grief reaction is accepted, then we may also assure that these parents must accomplish what Lindeman (1965) has described as the "tasks of Brief work" (p. 19). Summarized and reformulated so as to apply more precisely to the parents of the handicapped, these tasks are: 
1. Parents must accept the pain of their loss of the desired normal child.

2. They have to review their relationship with and revise their expectations for the handicapped child.

3. They have to become acquainted with the alterations in their own modes of ersotional responses.

4. They must work through these surprising feelings including the hostility they feel toward the defective child.

5. They will have to express their feelings of sorrow and sense of loss.

6. They will have to verbalize their feelings of guilt.

7. They will have to have persons around whon they can use as primers for new patterns of conduct.

Lindeman goes on to point out that one of the biggest obstacles preventing people from accomplishing these tasks successfully is their tendency to try to avold the intense distress and the necessary expression of emotion involved in grief work. The parents of handicapped children often avoid this work even more strenuously because they find the grief reaction unacceptable and unwarrented.

The most prevalent parental response to having a handicapped child mentioned in the literature is that of guilt. Wolfenberger (1967, pp. 330-31) offers five reasons why guilt is such a conmon phenomenon in these parents:

1. The parent feels guilty because of the anger and hostility he feels toward the defective child. Zuk (1962) made a similar point relating guilt to denial and inward turning of anger. 
2. Paxents may see the defect as a punishment for some past transgression. Sheimo (1951) concurs that parents may feel they are being punished for sins, real or imagined, and gives the example of a father of a retarded child who felt he was being punished for his love of garbling.

3. The third point made by Wolfenberger is that parents may harbor guilt over premarital, extra marital or unusual sex practices.

4. The child may have been unwanted in the first place or there may have been unsuccessful. attempts at abortion.

5. The parents nay feel guilty because of the homicidal inpulses they sometimes experience which are directed towards the child.

Covert (1965) feels that parental guilt feelings in such a situation seen almost universal conceptionalizing that having conceived the child, parents feel responsible for every aspect of his being. Morris (1954) sees over-concern, over-protection and over-indulgence as sacrifices that parents make in order to assuage their guilt feelings while Poznanski (1973) describes a viscious cycle of resentment, guilt and then over-protection which results in the additional problems of social passivity and immaturity in the defective child.

For many parents, a handicapping condition in their child is usacceptable and they attempt to act as if nothing is wrong with the child or to deny the existence of the defect. Gardner (1959) Einds it understandable that parents rely heavily upon the mechanism of denial in an attempt to avoid facing the severity and lifelong nature of the handicap, but points out the danger in denial in that it sets up parents to strive for external adjustment and inner freedom for anxiety based upon 
fictional beliefs. Begab (1963) and Sheimo (1956) see denial as an inportant parental defense mechaniam that is useful in the maintenance of self-esteem. Denial is more often seen in parents of retarded children than in parents of the physically disabled because the defect is less dascernable to casual observation and of ten the child "looks normal." But as Murray (1959) points cut, those parents who refuse to adnit theix child is retarded unst carry the double burden of grief and pretense, both of which tend to increase their internal emotional turnoil. In essence, denial on the part of parents can be seen as a method used to escape an unpleasant reality and as an attempt to avoid experiencing and expressing disquieting emotions.

Another defense commonly employed by parents of handicapped children is that of projection. Covert (1965) states that parents may blame the defect on some minor event in pregnancy or on the physician who delivered the baby or even on the habits of the husband or wife. Reid (1958) sees projection as a reaction to stress wherein parents strive to relieve themselves of full responsibility for the defect by finding fault with someone else. Perhaps the most destructive form of projection is when the parents pair off against each other in an attempt to find fault and avold responsibility.

Many people approach the parenting of a handicapped child with much ambivalence. Wolfenberger points out that all parents are ambivalent but that these feelings are stronger in the parents of the handicapped because a handicap in a child

is almost certain to make for more disappointment, grief, frustration and anger than one would experience in the parenting of a normal child. On the other hand the impulse to love 
and protect our children is deeply rooted in human values and probably instincts (p. 332).

Shield (1964) sees ambivalence as being sustained in parents by virtue of the fact that they can find no rational way to blame the child for his defect and, therefore, have no justification for the anger and hostility which they may feel for the child. Roos (1963) sees this ambivalence as contributing to depression inasmuch as the hostility toward the child may be redirected toward the self. He also feels that ambivalence can lead to defensiveness and over-protection stating that parents may become acutely sensitive to implied criticism of the child and may react with resentment and belligerance.

Gallagher (1956) has formulated four ways in which parental rejection of a handicapped child may be expressed:

1. The parents may establish strong underexpectations for the child because they feel he is basically worthless and incapable of progress.

2. The parents may set unrealistically high goals as a means of justifying their negative feelings and attitudes toward the child.

3. Escape, in which the parents withdraw from the child or institutionalize him without need.

4. Reaction formation wherein the negative parental feelings are so unacceptable that they attempt to adapt precisely to the opposite attitudes. This reaction formation is similar to what Roos (1963) has described as the masochistic position that some parents of handicapped children adapt. These parents seem to almost welcome the suffering they anticipate will accompany rearing the defective child. They think of 
themselves as "martyrs" who will devote all of their energies and sacrifice all pleasures for the child.

Wolfenberger has delineated three types of crises which parents of the handicapped may experience stating that some parents experience all of them, others one or none.

1. Novelty Shock Crises. This deals with the demolition of expectancies and resultant disorganization of the parents' adjustment.

2. Value crises. In a value crisis, the parents hold subjective views which make the child's defect unacceptable. Wolfenberger states that a value crisis usually leads to varying degrees of emotional rejection.

3. Reality Crises. In a reality crisis, forces which the parent. cannot control make it difficult to integrate the child into the home.

I. CRISES

The ways in which the parents react to and cope with their child's handicap will be determined by their own psychological dynamics, life orientation, and level of self-actualization as individuals. As Auerbach (1954, p. 18) has stated just because a parent may have a child who is severly ill or handicapped, he may not have a truly psychiatric problem in response to this situation. It often seems that professional workers look closer at the parents of the handicapped for signs of pathology than we would do with other parents and this may in and of itself contribute to the self-doubts and guilt feelings of these parents. Often parents are asked to accept their child's handicap or are evaluated in terms of their level of acceptance. Morris (1954, p. 514) has pointed out that 
acceptance often has a distorted meaning for parents in that they feel they are being asked to be as contented with a retarded child (or a child with any other handicap) as they are or would be with one who has normal potential. Acceptance is, however, a useful concept if we use it in reference to the parent's abilicy to assess the child's level of functioning realistically while still. recognizing that it is natural for them to react to the knowledge of a handicap as a very real crisis not only to the child but also to their own personal adjustment.

As the basic principles of pathological health and adjustment do not vary according to the specific problem that life brings to the individual and since we feel that having a handicapped child constitutes one of the most real and definite crisis that many individuals have to meet, we feel it is most useful to view parental response to this situation in terms of the crisis theory developed by Aguilera and Messick (1974). These authors view the individual's response to any crisis situation as being dependent on what they have termed three balancing factors. These factors are:

1. Perception of the event. It is theorized that if the stressful event is perceived realistically, there will be a recognition of the relationship between the event and the feelings of stress. If perception of the event is distorted, there may not be any recognition of a relationship between the feelings of stress and the event. In the case of parents of handicapped childrer, we can conceptualize that if the parents are able to recognize the fact that many, if not all, of their previous expectations must be abandoned and new ones adopted and at the same time link their feelings of guilt, anger, grief, etc., to this 
revision of expectations, then successful adjustment to the situation is probable. If on the other hand, the parent denies the handicap, sees no connection between it and his feelings, or finds his feelings of grief, ambivalence or any of the other possible responses in such a situation unacceptable, then his successful adaptation to the situation will be impaired.

2. Situation supports. Aguilera and Messick define situational supports as those people in the environmert who are available and who can be depended upon to help solve the problem. In the case of the parents of the handicapped, we can assume that those parents who have adequate situational supports, who have the opportunity to talk out treir feelings, and work through their grief, and who have the chance to meet with the other parents of handicapped children and discuss common problems will have a better chance for a successful and rapid adjustment than those parents who withdraw from social. contact out of feelings of guilt or shame and who have no opportunity for catharsis.

3. Coping mechanisms. Through the process of daily living, the Individual learns to use many methods to cope with anxiety and reduce tension at both a conscious and unconscious level. The available coping mechanisms are what people usually do when they have a problem. Parents who learn of a handicapping condition in their child face a novel stress producing event and their previous coping mechanisms are of ten ineffective, yet their adjustment to this crisis is in great part dependent on their previous adjustment and constitutional stability.

In Figure 1, we have reproduced with appropriate additions a paradigm constructed by Aguilera and Messick designed to show the effect 


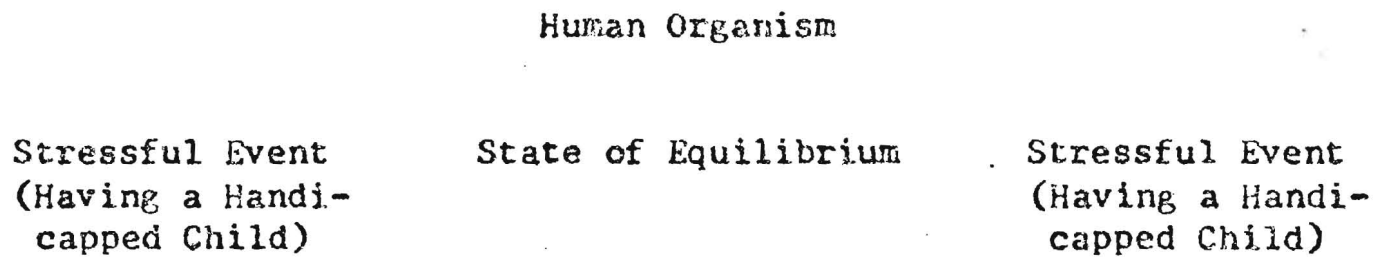

State of Disequilibrium

Felt Need to Restore Equilibrium

A

(Balancing Factors Present)

Realistic Perception of the Event

$+$

Adequate Situational Support

$+$

Adequate Coping Mechanisms

(Result In)

Resolution of Problem

(Successful Adaptation

to Handicapped Condition)

Equilibrium Regained

No Crises (Partial Resolution of Ongoing (rises)

Figure 1. Paradigms Effect of Balancing Factors in a Stressful Event.
Distorted Perception of the Event and/or

No Adequate Situational Support and/or

No Coping Mechanisms

Crises Unresolved

Disequilibrium Continues

Crises Perpetuated 
of the three mentioned balancing factors in adjustment to crises. This will hopefully illustrate the different paths which parents may take in adjusting to their child's handicapping condition. We, however, do not mean to imply that this adjustment is a singular event for we recognize that having a handicapped child inplies by its very nature that recurrent crises will take place at different life stages. However, we do maintain that there is an initial adjustment which parents must make to their child's condition so that they can best aid him in maximizing his potential.

We do not feel that we can overemphasize the importance of successfull parental adjustment in its impact on the adaptation of the handicapped child. If the child is overprotected or rejected, this in itself can produce emotional difficulties and behavior problens which are imposed upon the already existing physical or mental disability. If parents are unable to express and work through their feelings of anxiety, guilt, frustration, and grief, these feelings and the parent's discomfort will intensify, narrowing their perceptions to a crippling degree. The ablity to understand what is happening and make use of past experiences gives way to concentration on the disconfort itself resulting in a parent who is out of touch, both with himself and with his child. Parents who find themselves in this condition are unable to concentrate their energies on the needs of their handicapped child and as Berenberg (1959, p. 3) has writtens

In many ways the most critical need of a handicapped child from the beginning is a parent who can understand his problem and adjust to it. He needs not only parents who understand his condition, but as a result of this understanding, also foresee what his needs are going to be. 
We know that the quality and nature of the parental nurturance which a child receives will profoundy influenee his erotional development, his vulnerability to frustration, and the aggression, anxiety. helplessness, hopelessness and anger he experiences under various conditions (Lidz, 1968, p. 657). This is no less true for the handicapped than for the normal child nor should it be assumed that handicapped children are unable to detect how their parents feel towards them. Our observations tell us that these children usually sense how the parents feel and react accordingly.

In a study done by the California State Department of Education (1962), it was found that nost pertinent in an index of family acceptance or integration are those qualities in the parents themselves related to high self-esteem, low feelirgs of self-blame, and high affectional interchange between the child and both parents. Since it seems that parental qualities are predominant in determining adjustment and since successful adjustment must in our opinion precede the handicapped child's optimal development we feel that the best way to help the parent facing this special problem is to help him in his overall functioning as an individual. The better he is able to understand his own feelings and to act upon this understanding, the better able he will be to relate to the problem of his child's handicap in a healthy and constructive way. The child will tangentially absorb the benefits of his parents' selfactualization.

We have chosen Gestalt therapy as the most viable methodology within which to work in our attempt to assist these parents to higher levels of self-actualization. Its foundations, constructs, and the 
specific uses we have put it to in the parent education aspect of the "Tots" Program will be the subject of the succeeding chapter. 
FUNDAMENTALS OF GESTALT IN PARENT EDUGATION

Although there are different modalities for working with groups, Gestalt therapy was chosen as the most viable methodology to use in the "Tots" Parent-Education Program because of its techniques for intervention into self-defeating behaviors, and its usefulness in mobility and redirecting parental energy into self-supporting and creative development. Hendrik $M_{0}$ Ruitenbeck (1970, p. 114) states that "in the increased flooding of new group therapies...., the Gestalt therapeutic oriented approach to group therapy has been the most astute and perhaps the most successful of them all."

There are four important components of effective therapeutic oriented approaches in Gestalt therapy which make it adaptable to the "Tots" Parent-Education Program. They are (1) its theoretical and philosophical orientation, (2) harmony with the humanistic tradition of social work, (3) enhancement of personal levels of awareness, and (4) the knowledge and ability of the therapist to use Gestait techniques. For the purpose of this study, each component will be examined individually. Focusing first on the historical development of Gestalt and its theoretical and philosophical orientation to therapy.

Gestalt therapy developed out of three quite distinct sources and influences: psychoanalysis, particularly as modified by the early W1 Thelm Reich; European phenomenology-existentialism; and Gestalt 
psychology (Enright, 1970, p. 40). The founder of Gestalt therapy was Frederick S. (Fritz) Perls and Laura Perls who developed the goals, rechniques and concepes of Gestalt therapy.

The first account of this new therapy was published in 2947 by Fritz Perls in his book, Ego, Hunger, and Aggression. In it, he applied the basic principles of Gestalt and humanistic psychology, eastern spiritual thought, existential philosophies, Reichian body therapy, and psychodrama to underseand personality and developing a new psychotherapy (Resnick, 1974, p. 112; Grodner, 1974, p. 1).

Stella Resnick (1974, p. 112) points cut that

Gestalt is a German word meaning the whole, the entity formed by the particular order of its various parts. Gestalt psychology, which was well developed theoretical and research oriented school of psychology before Gestalt therapy was developed, proposed that the basic nature of human experience is that it is organized into patterns of gestalts.

A favorite slogan of the Gestalt school is that the whole is more than the sum of its parts. The basic premise being that human nature is organized into patterns of wholes, that it is experienced by the individual in these terms, and that it can only be understood as a function of the patterns or wholes of which it is made.

Frederick Peris in his book (Ego, Hunger, and Aggression) contrasts the themes of Gestalt psychology with that of Gestalt therapy by assimilating the psychological theories of configuration, structure, theme, structural relationship, and organized wholes into therapeutic application.

The theoretical and therapeutic core of Gestalt therapy is based on a holistic premise that 
the mind is the body and body is mind. The huran being is a gestalt, a unificd organism, and his or her mental and physical activities are manifestations of the sane thing, his or her total existence (Resnick, 1974, p. 112).

Looking at it from another perspective, Perls states that

the formation of complete and comprehensive Gestalten is the condition of mental health and growth. Only the conpleted Gestalt can be organized as an automatically functioning unit (reflex) in the total organism. Any incomplete Gestait represents an unfinished situation that clanors for attention and interferes with the formation of any novel, vital Gestalt. Instead of growth and development, we then find stagnation and regression (Perls, Hefferline, and Goodman, 1951, p. ix).

However, Gestalt therapy is not only a process of clearing up figure/ground disfunctionings, unfinished situations, projections, introjections, and other fixed ways of being that prevent spontaneity and choice; but it is also a therapeutic tool which can restore the natural equilibrium or smooth functioning of an individual by increasing his/her awareness of important organism--environmental transactions (Enright, 1970, p. 48).

John Enright (1970, p. 60) states:

Gestalt therapy considers the mentally healthy person as one in whom awareness can develop without blocking, wherever his organismic attention is drawn. Such a person can experience his own needs and the environmental possibilities fully and clearly from moment to monent accepting both as given and working toward creative compromises. He still has his full share of inner conflicts of needs and environmental frustrations, but, being in close touch with these developing needs and the environment, he is capable of achieving reasonably adequate solutions quickly and does not magnify his real problems with fantasy elaborations.

This approach towards looking at problems of maladjustment or the Inability to adjust to life situations differs quite distinctly from therapeutic theories and techniques of the past. Fagon and Shepherd 
(1970, p. 3) note that

in Gestalt therapy, the theory that people's problens arise from their lack of awareness leads directly to the therapist's focusing attention on the area and offering suggestions, tasks, and exercises designed either to promote avareness in general or to assist an individual with his specific avoid-m ances. Also, the patient's stated problens or concerns are translated directly into the therapy situation and in essence are demonstrated rather than simply described.

The implication of this process for parents of handicapped children is that Gestalt therapy, like any other therapy, will not be able to solve every problem at any given moment a parent may have, but can provide skills by which parents can contimue to grow on their own outside of the therapy situation in order to cope with conflicts as they arise. Basically, Gestalt therapy has two najor aims: assisting the individual to become more (1) self-aware and (2) self-responsible. Stella Resnick (1974, p. 11) defines these two aims stating that "selfawareness means knowing yourself, being tuned into what is happening within you at any moment." With arareness, people can recognize their natural, healthy tendencies. They can better distinguish between needs and wants; i.e., what feels good or bad, what old programs, old attitudes and habitual ways of doing things are no longer appropriate, and what new learning needs to take place.

"Self-responsibility means recognizing that you choose what you do and whom you are" (Resnick, 1974, p. 12). When individuals take responsibility for their lives, they enlarge their alternatives and learn to make choices that enhance and nourish them rather than deplete them. Blaming other people, the situation or fate are ways in which people do not take responsibility for themselves. In Gestalt therapy, 
we talk about the therapy process as one in which individuals learn to mobilize their own resources rather than ranipulate others to achieve or insure their well-being.

The philosophical-orientation that Gestalt therapy teaches, which Joen Fagan and Irma Shepherd (1970, p. 16) described very we11, asks the person to:

Listen to yourself, the stirrings, the movements inside; not to the words in your head; other people's vords, your parent's vords, society's words, cold, critical, directing words. Be aware of you, where you are, what you're doing; not the shoulds, the compands, the expectations. Keep your own eyes and ears, don't give them away and blind and deafen yourself. Don't give yourself away. Acknowledge what is yours. Hear the important messages inside you. Do you really need other's approval? See-without it, you still breath, still move. Breathe, move, look, listen, see. Move into yourself, your body. Move into direct contact with others. (Not into words, not into expectations.) Move into movement, into excitement, into nature, into flow, inco relaxation. Let it all in, all the richness, the fuliness. Live rich. Live full. Let it out, empty yourself. Let go. Find your emptiness, suffer your emptiness, enjoy your emptiness, fill your emptiness. Find your resources. Let go; hold on. Leave; come back. Push; let go. Let go now. Flow. Leave the games, the roles as empty skins behind. step out in nakedness, freedom. Find your rhythm; find your base; find your support. Support yourself. Reach out. Dare. Risk. Discover. Enjoy. Go freely into the now. Where else can you be but here? Who else can you be but you? You here now is enough. Be here. Be now. Be you.

Breaking Joen Fagen concepts down more explicitly as it relates to parents in the "Tots" Program, the value structure of this philosophical approach is:

1. To live now. The parent must be concerned with the present rather than with the past or future. What has been is already done and what will be is unknown. All we can really do is shape the here and now.

2. Live here. The parent aust deal with what, is present rather than with what is absent. 
3. Stop imagining. The parent must begin to experience the real.

4. Stop unneseary thinking. Rather, taste and see.

5. Express rather than manipulate, explain, justify, or judge.

6. Give in to unpleasantness and pain just as to pleasure. Do

not restrict awareness.

7. Do not accept any should's or ought to's other chan your own. Do not adore any graven images.

8. Take full responsibility for actions, feelings, and thoughts.

9. Last1y, surrender to being and functioning as you are.

These philosophical concepts of Gestalt therapy are in harmony

with the humanistic tradition of social work. Lyndell Louise Paul (1973,

p. 94) states that

the theory of Gestalt therapy is consonane with the systems theory of Parsons, Lewin, and Chin. It is applicable to approaches as diverse as transactional analysis, conjoint family therapy, reality therapy, and sensitivity training. In particular, Gestalt therapy offers vital theory and techniques for generating client self-support and responsibility-major goals of social work practitioners.

Furthermore, Gestalt is in harmony with the generic concepts of social work practice such as individualization, self-responsibility, self-determination, starting where the client is, empathy, acceptance, and confidence. By having these principles incorporated into its therapeutic theory, Gestalt therapy offers vital techniques for generatins client self-support, responsibility, and awareness by emphasis on (1) the therapist as authentic; (2) the client, free and responsible; and (3) on therapy, awareness of inter- and intra-personal processes. The process of Gestalt therapy consists of techniques which are step-by-step approaches to re-owning the disowned parts of the person- 
ality until the person becomes strong enough to facilitate his/her own growth. This process of Gestalt therapy is similar to the concept of self-actualization developed by Abraham Haslow and measured by the Personal Orientation Inventory which was developed by Everett Shostrom. Self-actualization is an ongoing process of self-awareness and the ability to express one-self fully at any given time.

The process of Gestalt therapy leading toward Maslow's concept of self-actualization is facilitated by a therapist who in turn uses a number of Gestalt techniques to bring about this process.

John Enright (1970, p. 41) states that

the task of the therapist using Gestalt techniques is to help the patient (in our case, parents) overcome the barriers that block awareness, and to let nature take its course (that is, awareness develops) so he/she can function with all his/her abilities.

The implications of this for the "Tots" Parent-Education Progxan is that the therapist's activities will be directed toward first, breaking up the parent's chronically and poorly organized field as it relates to the consequences associated with having a handicapped child. This process involves isolating portions of the way parents perceive or act in relationship to the child, and breaking the meaning of all of this into smaller subunits. This eventually will permit the parent to reorganize both their conceptual field and perceptual field in order to examine their "gut" feelings about the handicapped child. So that in Gestalt terminology, the parent is permitted to "finish" the most important "unfinished" situations. In other words, Joen Fagan's (1970, p. 46) states

the technique (of Gestalt therapy) is to establish a continuum of awareness. This continum of awareness is required so that 
the organism can work on the healthy gestalt principle: that the nost important unfinished situation will always emerge and can be dealt with. If we prevent ourselves fron achieving this gestalt formation, we function badiy and we carry hundreds and thousands of unfinished situations with us, that always demand completion.

Therapy basically consists of the reintegration of attending to awareness, with the emphasis placed on helping the parent develop his/ her own problem solving capacity rather than letting the therapist attempt to solve the problem. The tools that Gestalt therapists use in the process of therapy are awareness, experimenting, and encounter tenchiques. Each emerges out of the needs of each situation as it is presented. Because of the flexibility of Gestalt techniques, it becomes even more useful in a setting which combines behavioral management techniques along with general child-development education.

In utilizing Gestalt techniques in the "Tots" Parent-Education Program, the major objective of its incorporation should be to help the parent experience as much of themselves as they can and, that they experience themselves as fully as they can in the here and now. We do this so that the parents become more fully aware of their relationships, gestures, expressions and thought processes which they will communicate to their child in any parent-child interaction.

Claudio Naranjo (1973, p. 4) voicing an opinion about Gestalt techniques stated that

practicaliy every technique in gestalt therapy might be seen as a particularized embodiment of the broad prescription; be aware. This prescription, in turn, is an expression of the therapists belief and experience that only with awareness can there be true living, and that the light of awareness is all that we need to come out of our confusion, to realize the foolishness of the ones creating our conflict, to dispel the fantasies that are causing our anxiety. 
Adding to this statement, Fagar and Shepherd $(1970, p, 49)$ outine three layers or three zones of awareness: (1) awareness of the self, (2) avareness of the world, and (3) awareness of what's between the intermediate zone of fantasy that prevents a pesson from being in touch with either himself or the world. In another book, Life Techniques in Gestalt Therapy (1970, p. 207), Fagan and Shepherd explain the four main ways in which a person can block awareness. They are (1) retroflection, when the person opposes and holds back wishes, impulses, and behaviors, resulting in unfinished business; (2) desensitization of sensory and physical messages; (3) introjection of other's should's; and (4) projection of expectations, criticisms, etc. onto other people. In order to get at the core of conflicts, blocks and unresolved problems such as a parent not being able to accept their child's delay or handicapped condition, Gestalt has set up two sets of guidelines which are called for a lack of a better term, "rules" and "games." Levitsky and Perls (1970, p. 93) commented that the rules are few in number and are usually introduced and described formally at the outset of therapy. The games, on the other hand, are numerous and definitive lists are not possible since an ingenious therapist may well devise new ones from time to time.

Furthermore, states Perls (1970, p. 93) the

philosophy of rules is to provide us with effective means of unifying thought with feeling. They are designed to help us dig out resistances, promote heightened awareness--to facilitate the maturation process.

Example of rules used in the Gestalt process are:

1. The no-gossiping rule which is designed to promote feelings and 
to prevent the avoidance of feelings. Gossiping is defined as talking about an individual when he is actually present and could just as well be addressed directly.

2. The rule of no-aboutism is composed of rules against giving or searching for explanation, philosophizing, or searching for a truth other than evidence, no personality diagnosis, or gathering of information conducive to interpretation plus discussion of the weather, the morning news, etc.

3. Rules concerning the asking of questions direct attention to questions which are genuine and can be distinguished from those questions which are hypocritical. The latter questions are intended to maripulate or cajole the other into seeing or doing things in particular ways. On the other hand, questions in the fortn of "how are you doing"? and "are you aware that ..."? provide genuine support.

4. Rules concerning the use of the awareness continuum concentrates on the ability of the therapist to move the patient away from the emphasis on the why of behavior (psychoanalytic interpretation) and toward the what and how of behavior (experiential psychotherapy).

5. Rules concerning "it" language and "I" Ianguage. This rule deals with the semantics of responsibility and involvement. It is common for us to refer to our bodies and to our acts and behaviors in the third person, "it," language. Through the simple and seemingly mechanical expedient of changing "it" language into "I" language, we learn to identify more closely with the particular behavior in question and to assume responsibility for it. The process of changing "it" to "I" is an example in microcosm of many of the Gestalt game techniques. 
6. Rules concerring the "it" and "thou" with the "I" and "thou" principle, the therapist strives to direct as conctetely as possibie the notion that true commication involves both sender and receiver. The parent often behaves as if aimed at the blank wall or at thin air. Therefore, the cherapist uses the skill to direct the communieation inside the group. The parent is asked to be aware of the distinction between talking "to" and talking "at" the listener.

If at any time during the process of therapy, the parent fails to abide by a rule that has already been accepted, Claudio Naranjo (1973, p. 13) wentions that we ray infer the following:

1. At that point the parent is experiencing something that he/she must avoid.

2. That the parent's desire to play "see how clever I am" or a similar game is stronger than his desire to share his experience.

3. That he dares not trust the therapist and/or the method employed by him.

In Gestalt therapy, parents are encouraged to put their words and feelings into action, and to pay attention to themselves as they do so. This process is stimulated through the use of games which allows the parent to play-out their unresolved feelings and conflicts. It is similar in some aspects to the theories and concepts developed by play therapists such as Virginia Axline (1969) and Clark E. Moustakas (1959) who developed the concepts of play therapy with children in order to assist them in overcoming conflicts.

Similarly, Gestalt therapy uses games to assist in the therapeutic process of making the individual more aware of his/her thought processes, 
feelings, and adaptation to social roles. According to Perls (1970, p. 104), "a great deal of our thinking consists of internal rehearsal and preparation for playing our accustomed social roles. The experience of stage fright simply presents our fears that we will not conduct our roles wel1."

In the therapeutic prosess, the therapist uses games skilliully to separate conflicts into their duality and their subsequent re-enactment leads after a series of dialogues to the resolution of the conflict. The key to this whole process of conflict resolution and the underlying theory of using games in the therapeutic process is to bring the parents to the stage commonly described by Gestaltist's as the "impasse phenomenon."

Ruth Cohn (1970, p. 89) describes the impasse phenomenon as the "ultimate expression of two strivings pulling in opposite directions." This experience usually leads to the feelings of blankness, confusion, and helplessness. However, it is the impasse phenomenon that was Perl's most important and unique contribution to psychotherapy. He illustrates that when the patient can endure and experience the extent of his feelings of confusion, blankness, impotence, etc., organismic change takes place. The deaning of this as it relates to the parents of handicapped children is that once the impass has been reached and the grieving process has been completed as described earlier by Wolfensberger, the parents can then begin to reorganize their lives. They can accept themselves and their child without the burden of unresolved conflicts.

For the purpose of lilustrating some of the procedures in games leading to an intensification of action, four types of procedures are 
Iisted below as outlined by Claudio Naranjo (1973, pp. 40-1). They are:

1. Simple repetition.

2. Exaggeration and development.

3. Explicitation or translation.

4. Identification and action.

Simple repetition is described as a method of intensifying the person's awareness of a given action or statenent and may be seen as a step beyond the therapist's action of simply mirroring or reflecting. The technique of repetition can be adapted to the group situation by addressing the repetitive statement or action to different members. There are several variations of this exercise:

1. Strict repetition, for instance; saying good bye to each person present.

2. Strict repetition followed by elaboration according to the way the statement applies to the person in question.

3. Repetition of content, adapting the form of the statement to each person.

4. Repetition of attitude with variation in content. (i.e., expression of anger in whatever way seens fit according to the individual encountered). (Naranjo, 1973, p. 40)

The second procedure is that of exaggeration and development. Exaggeration is one step beyond simple repetition and frequently takes place spontaneously when a person is asked to do or say something a number of times.

When a person is asked to exaggerate and does this a number of times, he/she may discover something new in his action. This may not be 
a completely new quality, but one which was hidden in his original behavior like an invisible seed so that only exaggeration can make it. obvious.

In the developrent aspect, the therapist instructs the parent to develop thoughts and staternents,

to explore the trend of their movenent, gesture, posture, vocal. sound, or visual image. In this way, the urge, only imperfectly expressed in a fleeting action, may reveal itself fully in a sequence which may at times constiture a piece of dance, music, or poetry. (Naranjo, 1973, p. 41).

The third procedure is that of explicitation or translation, which the therapist generally introduces with statements such as "give vords to your nodding," "if your tears could speak what yould they say"? "what would your left hand say to your right hand,"? or "give a voice to your loneliness." In doing so, the parent is being urged to translate into words a piece of non-verbal expression--a gesture, visual image, physical symptom, etc. He is thus requested to make explicit content which was only implicit.

In the process of explicitating, the parent must necessarily empathize with that aspect of himself or his perception that he tries to put into words. He must, so to speak, experience the event from the inside rather than as an external onlooker. The result may be surprising when applied to the perception of persons or dream images, both of which are screens for our projections.

Last of the game techniques is that of identification and acting. Acting is an important part of Gestalt therapy both in the external sense of going through the motions that fit a given role and in the inner sense of experiencing oneself as another, imagining oneself as possessing the 
attributes or actions of other beings or things.

In the sense that action gives motoric expression to an idea, feeling or image, it may be regarded as one more instance of translation from one expression modality to another. Acting, therefore, may be understood as an implementing expression.

What the Gestalt therapist is doing when he asks a parent to act out his memories or expectations is equivalent to asking him to carry out physically an action that he is carrying out repetitiously. Sometimes, in fantasy, while doing so the patient nay discover that he is hanging on to that particular memory or fantasy as a consequence of its very "unfinishedness"--an urge to take action, chronically prevented and substituted by half-hearted rehearsing.

In an inner sense, acting entails a process of identification, or becoming one with the part that we act or recognizing "its" experience as our own. The instructions "be him," "be your hand," "be your voice," etc., are one step beyond the empathy required by explicitation. Through the use of techniques and games as Stella Resnick states, (1974, p. 117)

Gestalt therapy can become not only a clearing of the unfinished business, the projections, the introjections and the fixed way of being that prevent spontaneity and choice, but it is also a training in the skills by which people can continue to grow on their own, outside the therapy situation.

Even when they are not involved in any on-going therapy experience, parents can continue to practice and develop the ability to learn from themselves through noncritical self-observation, to trust their bodies and the natural expression of their feelings, to risk exploring new and different ways of being in the "here and now." 
Gestalt therapy does heve some limitations, as do all therapies in use today. Before moving into the next chapter, these ligitations will be briefly discussed.

The most immediate limitation of Gestalt therapy was pointed out by Fagan and Shepherd (1970, p. 200), when they wrote that like any other therapy, the skills, training, experience, and judgement. of therapy rests basically on the ability of the therapist. Since Gestalt techniques facilitate access to and release of intense affect, a therapist using this approach must neither be afraid nox inept in allowing the patient to follow through and finish the experience of grief, rage, fear, or joy. The capacity to live in the present and to offer solid presence standing by are essential.

Another liritation is that the consequences of successful Gestalt therapy may be that by teaching the parent to be more genuinely in touch with himself, he will experience more dissatisfaction with conventional goals and relationships. He may experience for the first time the full pain, previously denied, that having a handicapped child may entail. Last1y, since Gestalt techniques, in general, facilitate the discovering, facing, and resolution of the parent's major conflicts in a dramatically short time, the inexperienced therapist, observer, or parent may assume that Gestalt therapy offers an "instant cure." This may result in pseudointegration and subsequent disappointment if the level of self-actualization cannot be maintained. 
CHAPTER V

THE USE OF THE PERSONAL ORIENTATION

INVERTORY AS AN EVALUATION TOOL

Up to this point, this paper has focused on parental reactions to having a handicapped child and the use of Gestalt technique in a ParentEducation Program designed for these parents. It is now the intention of this paper to introduce and discuss a tool which nay prove useful in evaluating the effectiveness of using Gestalt techniques in this program. The instrument chosen as most appropriate to this task is the Personal Orientation Inventory (POI) which was developed in 1963 by Everetr L. Shostrom.

The POI was designed as an inventory for the measurement of selfactualization and finds its theoretical base in the works of Abraham Maslow, Carl Rogers, and Frederick Perls in addition to other writers of Humanistic, Existential and Gestalt orientations. It is not intended as a measure of pathology but is rather designed to reflect the subjects level of positive mental health through measurement of values and behavior hypothesized to be important in the developrent of the fully functioning self-actualizing person.

The POI consists of 150 two choice items which call on the subject to make various comparative values and behavior judgments. The items format is one of paired opposites which presents each statement in terms of a positive and negative aspect of the continuum or dichotomy in question. 
The items are scored on two basic scales, Inner-Directed Support and Time Competence. The support scale is designed to measure whether an individual is characteristically "self" oriented or "other" oriented. Shostrom (1964) describes inner or self directed individuals as being guided primarily by internalized principles and motivations, while ocher directed persons are to a great extent influenced by external forces. The time competence scale measures the degree to which the individual lives in the present as contrasted with the past or future and is in great part based on the formulations of Fritz Perls. The person who is time competent has full awareness in the present moment and is less burdened by guilts about the past or obsessions with the future than is the time incompetent person. The time competent person lives in the "here and now" and is able to tie his past and future together in some type of meaningful continuity.

In addition to the Time Competency and Inner-Directed Support scales, there are ten other subscales within the POI which evaluate areas deemed important to self-actualizarion. The first of these subscales is Self-Actualizing Values (SAV) which is based predominately on the work of Abraham Maslow and is designed to measure the extent to which the subject identifies with values commonly held by self-actualizing individuals. Existentiality $(\mathrm{Ex})$ is the second subscale and it is intended to measure the rigidity with which the subject applies his values. Feeling Reactivity (Fr) measures sensitivity of responsiveness to ones own needs and feelings while Spontaneity (S) measures to what extent the subject feels free to be himself. Self-Regard (Sr) measures how much one likes oneself while Self-Acceptance (Sa) measures the subjects abilizy to 
accept his own weaknesses and limitations. Nature of Man (No) measures the degree to which the subject holds a constructive view of mankind and Synergy (Sy) measures the ability to transcend dichotomies (i.e., love vs. hate). Acceptance of Aggression measures the ability to accept one's natural aggression while Capacity for Contact (c) measures the subjects ability to establish meaningful relationships with other human beings.

\section{ADMINISTRATION AND SCORING}

The $P O I$ is self-administering and can be administered individually or in groups. The test is not timed and usually takes approximately 30 minutes. It is considered appropriate for individuals with a mental age of 14 and above. It may be hand or machine scored and the raw scores may be plotted on a profile sheet which will automatically convert them to standard scores based on adult norms. Interpretation of the POI may be done on an individual basis or the meaning of profile patterns may be presented in group sessions. In either case, the POI is designed so as to make it easily interpretable to the client.

We suggest that the POI can serve as an effective pre- and posttest for those parents exposed to the Gestalt component of the ParentEducation Progran. In this way, initial levels of self-actualization could be plotted for each parent prior to the program and later compared to his/her retest scores to show changes in any or all of the subscales. These scores could be compared to a control group which would be administered in the same manner but would not be exposed to the Gestalt techniques. In this anner, the effectiveness of the use of Gestalt therapy in the Parent-Education Program at the Child Development and 
Rehabilitation Center could be evaluated.

Precedent for use of the POI in this manner has been set by various authors. Reddy (1973) examined changes in the PoI over time for three sensitivity groups, cach composed of 12 male YMCA administrators. Members of the ten-day residential groups completed the POI before their first meeting, before their last meeting, and one year after the group ended. Although control groups were not utilized, all three groups recorded changes on the POI over time. White (1974) administered the POI to 85 community college students who participated in a 12-week human potential laboratory and to 74 students who did not participate. Preand post-test data indicated that laboratory participants made significant gains on four of the twelve POI scales.

Young and Jacobson (1970), in studying the effects of time-extended marathon groups on personality characteristics, administered the Edwards, and Maslowe-Crowne Social Desirability scales and the POI to seven undergraduates four days before the four days after participating in a 15hour marathon group experience. In a comparison with seven control subjects who received the same tests without the intervening group experience, it was found that participants in the marathon group demonstrated a significant decrease in defensiveness and constriction and showed changes in the direction of more socially positive functioning on 13 of the 14 scales employed.

Culbert, Clark, and Bobele (1968) used the POI to measure changes toward self-actualization in two sensitivity groups but didn't find any changes in the self-actualizing behavior. In two studies done at Bowling Green State University by Foulds (1970) and Guinan and Foulds (1970), the 
POI was used as a pre- and post-test instrument to measure changes resulting from involvement in a nine-week personal growth group and a weekend marathon group respectively. In both instances, some growth towards self-actualization as masured by the POI was observed. It should be noted that in both of these instances the therapists involved held a Gestalt orientation and utilized this treatment modality in their work. In a study done by Lewis (1968), the POI, along with first semester grade point averages, were used to evaluate the effectiveness of using small group procedures as aids to the adjustment of entering college freshman. Specific focus was on the relative effectiveness of three small group treatments with the conclusion that students do seem to make better adjustment to college through the vehicle of small group procedures with relatively permissive armospheres. Another conclusion of this study was that students who participate in the threat free climate of a small group tend to make better grades than students in larger groups. Stockton (1969) utilized the verbal score on the Scholastic Aptitude Test, the pre- and post-tests of the POI, and the Minnesota Teacher Attitude Inventory in order to determine the relative effectiveness of sensitivity training in the pre-service education of teachers. The results of the study showed that the mean scores of the experimental and control groups on the POI Time and Inner Direction scales did not differ significantly, although the time scale mean scores did show some tendency towards significance in the interaction effects of sex and ability level and sex and sensitivity training. Groeneveld (1969) used the POI as a pre- and post-test instrument in a study of the positive-experience Broup encounter and its effect upon self-actualization. Two groups, one 
using conventional group methods and the other which emphasized sharing positive experiences from the past, met for a ten-week period. Both groups changed significantly in a positive direction on the POI but there wasn't any significant difference in the growth patterns of the experimental as compared to the control group which used conventional group procedures. It was, therefore, the authors' conclusion that both treatment methods were equally effective in the facilitarion of self-actualizing behavior.

If the use of the POI in evaluating the effectiveress of using Gestalt techniques within the "Iots" Program is to be sound, several fundamental issues basic to research design must be considered. First, random assignment of subjects to the experimental and control conditions is highly desirable for the interpretation of results. That is to say, steps must be taken to ensure those subjects selected to receive exposure to the Gestalt techniques and those selected for the control group should be selected at random from the same sample population. In the case of the "Tots" Program, this requirement could be met by utilizing a random selection of parents based on the tots waiting list.

Secondly, an analysis of attrition effects would be seen as vital to maintaining the validity of any such study. In regard to an analysis of the effect of using Gestalt in the "Tots" Program, it is projected that the sample $\mathrm{N}$ for both the therapy and control groups would not exceed twelve each. Where such a small sample $N$ exists, the effect of one or more members dropping out will almost certainly have a statistically significant effect and as such data on these individuals should be included in the tabulation of study results. 
Thirdly, the maintenance of some measure of independence between the experimenter and the group leader should be followed. The group leader should dissociate hinself from the administration, scoring, and interpretation of the test so that testing bias can be avoided in both the experimenters and the test subjects. It is suggested that the group leader be absent from both the pre- and post-test as his presence could be seen as influencing subject's rest responses in an unpredictable manner.

The use of the POI in a pre- and post-test research design has several limitations which we can anticipate. Perhaps the most serious linitation of any research designed to measure comparative changes is the unreliability of raw change scores. Secondly, the possibility of testing bias is real in that subjects may attempt to answer the posttest according to their recall of their pre-test responses, either in an attempt to present a picture of stability (fake-same) or in an attempt to present a picture of growth (fake-different). It is our contentions that testing bias can be largely controlled by taking care in precisely stating the test instructions, avoiding subjecting participants to social pressure or indoctrination, and by making it clear that subjects have no vested interest in the outcome of their individual tests. In this vein, it may be most useful to point out to the subjects that it is group scores and not individual scores which will be of most interest to the experimenters. It is most important that extreme caution in interpretation be exercised if the POI is used with a population (such as social worker trainees) sophisticated in the theory on which it is based, although we assume that this will not be the case in the "Tots" Program. 
A further question may be raised regarding whether response bias associated with people learning to "talk the right gane" will artificially enhance post-test scores. This is seen as a minimal limitation in that Gestalt therapy requires little change in participants vocabulary and emphasizes feelings rather than jargon. Furthermore, the basis of Gestalt is an avoidance of intellectualization in favor of placing the focus of therapy on getting the patient more fully in touch with both his internal feelings and with the external reality. The Gestalt therapist hasn't any expectations of what his patient should be and is, therefore, unlikely to try and mold or shape hin to meet his expectations. In Gestalt, the person is asked to become more fully aware of hinself as he is, not as the therapist expects him to be.

A final limitation of the proposed study concerns the adequacy of using one self-report instrument to measure group change. In this light, it would be laudable and useful to develop some type of behaviorreferenced measures that might be used as indexes of impact but such an undertaking is far beyond the scope of the present paper. Furthermore, it is our contention that both, in terms of historical precedent and statistical validity and reliability, our use of the PoI in the proposed study is justified. In general, the content validity of the scales of the POI is good and the variables being assessed by the items are broadly defined. Shostrom addresses himself to the topic of the PoI's concurrent validity in the test manualy citing numerous studies in which the POI was found to be capable of differentiating self-actualized, normal, and non-self-actualized individuals significant at the .01 confidence level. Shostrom employs another form of concurrent validity 
by attempting to determine how well the instrument correlates with other measures purporting to measure similar traits. However, since there arent any other measures designed to masure self-actualization per se, it was necessary to base the validity primarily upon correlations with measures of general pathology. Studies cited in this vein are those by Shostrom and Knapp (1966), in which the POI was correlared with certain scales of the MMPI, and another study by Knapp (1965) where the PoI was correlated with the Eysenck Personality Inventory and in which all mean differences vere significant at or beyond the .05 level. Other studies cited to substantiate validity are those of May and Ilardi (1968) and Dandes (1966).

The major psychometric data related to reliability that is reported in the manual are test-retest reliability correlations and normative data. The reliability coefficients range from a moderate .55 to a good 85. It should be noted that the normative data reported in the manual are somewhat biased towards the college student population. The standard score profile sheet is based on norms of 2.607 entering college freshman and three out of nine group profiles presented are for college groups.

\section{CONCLUSION}

In conclusion, it is our contention that the POI is the only instrument currently in broad use which is capable of measuring the effect of using Gestalt therapy with parents of handicapped children. Providing that our recommendations are carefully followed in outlining the research design, a pre-test, post-test design utilizing the Personal Orientation Inventory will furnish the experimenter with a 
good deal of data which he may utilize in evaluating the effectiveness of the specific treatment modality in question. 
Aguilera, Donna C. and Janice M. Messick 1974. Crises Interventions Theoty and Pethodology.

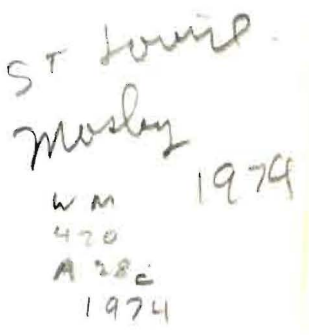

Alierbach, A. B. 1959. "What Can Parents of Handicapped Childreit Gain from Group Experience?" Helping Parents of Handicapped Children: Group Approaches.

Axline, Virginia 1969. Play Therapy.

Begab, Michael J. 1963. "Casework for the Mentally Retarded--Casework with Parents," The Mentally Retarded Child: B Guide to Services of Social Agencies.

Berenberg, William 1959. "What are the Needs of the Handicapped Child," Helping Parents of Handicapped Children: Group Approaches.

California State Department of Education 1962. "Parent Attitudes in Rearing Mentally Retarded Children."

Covert, Cathy 1965. "Mental Retardation."

Culbert, Samuel A., James V. Clark and H. Kerneth Bobele 1968. "Measures of Change Toward Self-Actualization in Two Sensitivity Training Groups," Journal of Counseling Psychology, XV, 53-57.

Cummings, S. T.s H. C. Bayley and H. E. Rie 1966. "Effects of the Child's Deficiency on the Mother: A Study of Mentally Retarded, Chronically III and Neurotic Children," American Journal of Orthopsychiatry, XXXVI, 595-608.

Dandes, H. M. 1966. "Psychological Health and Teaching Effectiveness," Journal of Teacher Education, XVII, 301-306.

Enright, John 1970. "Introduction to Gestalt Techniques," Life Techniques in Gestalt Therapy.

Fagan, Joen and Irma Lee Shepherd 1970. Life Techniques in Gestalt Therapy.

Fagan, Joen and Irma Lee Shepherd (Ed.) 1970. Gestalt Therapy Now.

Foulds, Melvin J. 1970. "Effects of a Personal Growth Group on a Measure of Self-Actualization," Journal of Humanistic Psychology, $x, 33-38$. 
Frankl, Victor 1962. Mans Search for Meaning.

French, Anne C., M. Levburg and H. Michael-Smith 1953. "Parent Counseling as a Means of Improving the Performance of a Mentally Retarcied Boy: A Case Study Presentation " American Journal of Mental Deficiency, LVIIX, 13-20.

Gallagher, James J. 1956. "Rejecting Parents?" Exceptional Children, 122.

Gardner, George E. 1959. "The Psychiatric Considerations Underlying Parental Concern for Handicapped Children," Helping Parents of Handicapped Children: Group Approaches.

Grodner, Brian 1975. "Gestalt Therapy: A Study Guide and Annotated Bibliography."

Groenveld, Leroy Charles 1970. "The Positive Experience Group Encounter and Its Effect on Self-Actualization," Dissertation Abstracts International, $\mathrm{XxX}, 3726-\mathrm{A}$.

Grow, M. S. 1967. "Preventative Intervention Through Parent Group Education," Social Casework, XLVIII, 161-165.

Guinan, James F. and Melvin L. Foulds 1970. "Marathon Group: Facilitator of Personal Gxowth," Journal of Counseling Psychology, XVII, 145-149.

Knapp, R. R. 1965. "Relationship of a Measure of Self-Actualization to Neuroticism and Fxtraversion," Journal of Consulting Psychology. $\mathrm{XXIX}, 168-172$.

Levitsky, Abraham and Fritz Perls 1970. "The Rules and Games of Gestalt Therapy," Life Techniques in Gestalt Therapy, 93-107.

Lewis, Sinclaix 0. 1969. "A Test of Small-Group Procedures in College Adjustment," Dissertation Abstracts International, XXX, 2337-A.

Lidz, Theodore 1968. The Person.

Lindeman, Eric 1965. "Symptomatology and Management of Acute Grief," Crisis Intervention.

Maudelbaum, Arthur 1967. "The Group Process in Helping Parents of Retarded Children," Children, XIV, 227-232.

May, W. T. and R. L. Ilardi 1968. "A Reliability Study of Shostron's Personal Orientation Inventory," Journal of Humanistic Psychology, 68-72.

McDonald, Eugene 1971. "Understand Those Feelings," Counseling Parents of the III and Handicapped. 
Morris, Elise F, 1954-55. "Casework Training Needs for Counseling parents of the Retarded," American Journal of Mental Deficiency, LIX. Jan 55 J10-516

Moustakas, Clark 1953. Children in Play Therapy.

Murray, M. A. 1959. "Needs of Parents of Mentally Retarded Children," American Journal of Mental Daficiency, LXIII, 1078 1088.

Naranjo, Claudio 1973. The Techriques of Gesta2t Therapy.

Olshansky, Simon 1962. "Chronic Sorrow: A Response to Having a Mentaily Defective Child," Social Casework, XIIII, 191 w194.

Olshansky, Simon 1966. "Parent Responses to a Mentally Defective Child," Mental Retardation.

Paul, Lyndell Louise 1973. "The Relevance of Gestalt Therapy for Social Work," Clinical Social Work Journal, I, 94-99.

Perlnan, Helen H. 1963. "Social Work in Child Health Projects for Nentally Retarded Children," National Heeting for Social Vorkers In Maternal and Child Health Services for Mentally Retarded Children.

Perls, Frederick (Fritz) 1947. Ego, Hunger and Aggression.

Per1s, Fritz, Ralph Hefferline, and Paul Goodman 1951. Gestalt Therapy.

Perls, Fritz 1970. "Dream Seminar," Life Techniques in Gestalt Therapy, 165-199.

Poznanski, Elva 0. 1973. "Emotional Issues in Raising Handicapped Children," Rehabilitation Literature, XXXIV, 322-326.

Reddy, W. Brendan 1973. "The Impact of Sensitivity Training on SelfActualization: A One Year Follow-Up," Small Group Behavior, IV, $407-413$.

Reid, Eleanor S. 1971. "Helping Parents of Handicapped Children," Counseling Parents of the III and Handicapped.

Rheingold, Harriet 1945. "Interpreting Mental Retardation to Parents," Journal of Consulting Psychologist, IX, 142-148.

Resnick, Stella 1974. "Gestalt Therapy: The Hot Seat of Personal Responsibility," Psychology Today, 111-1i8.

Roos, Philip 1963. "Psychological Counseling with Parents of Retarded Children," Mental Retardation, I, 345-350. 
Ruitenbeck, Hendrik M. 1970. The NeH Group Therapies.

Ryckman, David B. and Robert A. Henderson 1965. "The Meaning of a Retarded Child for his Parents: A Focus for Counselors," Mental Retardation, III, 4-7.

Schild, Sylvia 1964. "Counseling with Parents of Retarded Children Living at Home," Social Work, IX, 86-91.

Sheimo, S. L. 1951. "Problems in Helping Parents of Mentally Defective and Handicapped Children," American Journal of Mental Deficiency. LVI, 42-47.

Shoemaker, Louise 1963. "Social Hork with the Mentally Retarded," Presented at the National Meeting for Social Workers in Maternal and Child Health Services for Mentally Retarded Children.

Shostrom, Everett L. 1964. "An Inventory for the Measurement of SelfActualization," Educational and Psychological Measurement, XXIV, 207-218.

Shastrom, E. L. and R. R. Knapp 1966. "The Relationship of a SelfActualization (POI) to a Measure of Pathology (MMPI) and to Therapeutic Growth," American Journal of Psychotherapy, $\mathrm{xX}$, 193-202.

Solnit, A. J. and Mary H. Stark 1961. "Mourning and the Birth of a Defective Child," The Psychoanalytic Study of the Child, XLI, 523-537.

Stockton, Rex Arthur 1970. "An Investigation of the Effect of Sensitivity Training on the Attitudes of Teacher Education Students," Dissertation Abstracts International, $\mathrm{XXX}, 3726-\mathrm{A}$.

White, John 1974. "The Human Potential Laboratory in the Community College," Journal of College Student Personnel, XV, 96-100.

Wille, Blanche M. 1961. "Tue kole of the Social Worker," American Journal of Mental Deficiency, LXVI, 464-467.

Wolfenberger, Wolf 1967. "Counseling the Parents of the Retarded," Mental Retardation: Appraisal, Education, and Rehabilitation, Chapter 13, 329-400.

Young, Edward R. and Leonard I. Jacobson 1970. "Effects of Time Extended Marathon Groups on Personality Characteristics," Journal of Counseling Psychology, XVII, 245-251.

Zuk, G. H. 1962. "Cultural Dilema and Spiritual Crises of the Family with a Handicapped Child," Exceptional Children, XXVIII, 405-408. 